\title{
Racial distribution of Duchenne muscular dystrophy in the West Midlands region of Britain
}

\author{
Alison Roddie, Sarah Bundey
}

\begin{abstract}
In the West Midlands region of Britain, Duchenne muscular dystrophy (DMD) is twice as common as expected in Indians, and is less common than expected in Pakistanis. Although the numbers are small, they cannot be explained by any bias of ascertainment and are considered to be real. One possible mechanism for the high frequency of DMD in Indians is the presence of repetitive elements in the wild type gene which predispose to mutations.
\end{abstract}

Through the Genetic Register for Duchenne muscular dystrophy (DMD) in the West Midlands health region of Britain an impression was gained that there was an increased incidence of the disorder in Indians. This was strengthened by the unusual occurrence of three mutations of different dystrophin genes in a single Malaysian Sikh family. ${ }^{1}$ We therefore carried out a population study to discover whether DMD is more frequent in Indians than in other races.

\section{Methods}

A Genetic Register for Duchenne muscular dystrophy was set up in 1977 and since then efforts have been made every two or three years to obtain complete ascertainment. Nevertheless some patients are still not referred to the Register, particularly if there are no females at risk for being carriers. Therefore we made additional efforts to ascertain all patients by checking the case records of the two muscular dystrophy care officers who serve the West Midlands, and by writing to all paediatricians. We excluded the English/Sikh boy who was one of the reasons for the study being instigated, and who has been reported by Miciak et al. ${ }^{1}$ We have also excluded two females who are severely manifesting Duchenne carriers. We considered our prevalence figures for 1970 to 1985 to be reliable.

We considered the data in two ways. Firstly, we wished to use all our data for years of birth

Table 1 Birthplace of head of household for children aged 0 to 4 years (West Midlands data obtained from 1981 census, tables 11).

\begin{tabular}{lcrrrr}
\hline & East Africa & India & Pakistan & Caribbean & All birthplaces \\
\hline West Midlands conurbation & 1714 & 14967 & 10852 & 4841 & 161731 \\
Hereford and Worcester & 44 & 111 & 291 & 125 & 39206 \\
Staffordshire & 96 & 329 & 945 & 184 & 62428 \\
Shropshire & 47 & 193 & 125 & 80 & 22960 \\
Warwickshire & 215 & 1024 & 59 & 84 & 27714 \\
Total & 2116 & 16624 & 12272 & 5314 & 314039 \\
\hline
\end{tabular}

1970 to 1985 to compare our observed racial distribution to that expected. The expected racial distribution of patients was largely obtained from the 1981 census $^{2}$ where we used head of household figures for children aged 0 to 4 years (table 1). Unfortunately, the next age group ( 5 to 15 years) would have extended into the period before 1970 for which our records were incomplete, but we noted that its proportions of Indians and Pakistanis were less than in the 0 to 4 age group. We classified our Duchenne patients by the country of origin of their parents (India, or Pakistan, or the Caribbean) and not by their birth places. We therefore had to adjust the head of household data for those ethnic minority parents expected to have been born in the UK on the basis of data collected in Birmingham in $1986^{3}$ (table 2). We also adjusted for the fact that in $198151.5 \%$ of children were boys and we thus calculated that $6.9 \%$ of young West Midlands boys in 1981 would be Indians, $4.1 \%$ would be Pakistanis, $2.5 \%$ would be Afro-Caribbeans, and $86.5 \%$ would belong to other races, including English and mixed races (table 2). The expected ratio of pure Afro-Caribbeans to the offspring of mixed English/Afro-Caribbean unions is 6:1. ${ }^{3}$

The second analysis involved estimating the incidence of DMD among boys born in a short period (1978 to 1981) in which fluctuations owing to movement of populations would be minimised. Effectively this would give the birth frequency of DMD over four years on the assumption that there was no excess of migration in, or migration out (including deaths), of one racial group disproportionately to any other racial group. All patients born in this period should be diagnosed as having DMD by the time of analysis (1991).

\section{Results}

There was a total of 176 boys with DMD who had birth dates from 1970 to 1985 inclusive. These comprised 24 Indians (13.6\%), three Pakistanis $(1.7 \%)$, one Afro-Caribbean $(0.6 \%)$, and 148 boys of other races, who included three who were the offspring of Afro-

Unit, Birmingham

Maternity Hospital,

Edgbaston,

Birmingham

B15 2TG.

A Roddie

$S$ Bundey

Correspondence to

Dr Bundey.

Received 26 November 1991

Revised version accepted

24 February 1992. 
Table 2 Racial origin of boys aged 0 to 4 in 1981 in the West Midlands.

\begin{tabular}{|c|c|c|}
\hline \multirow{2}{*}{$\begin{array}{l}\text { Birthplace of head } \\
\text { of household }\end{array}$} & \multicolumn{2}{|c|}{$\begin{array}{l}\text { Males aged } 0 \text { to } 4 \text { in } 1981 \\
(1978-1981 \text { inclusive })\end{array}$} \\
\hline & No & $\%$ \\
\hline $\begin{array}{l}\text { All birthplaces } \\
\text { India/East Africa } \\
\left(+15 \cdot 1 \% \text { for UK births }{ }^{3}\right)\end{array}$ & $\begin{array}{r}161731 \\
11108\end{array}$ & $\begin{array}{l}100 \\
6 \cdot 9\end{array}$ \\
\hline $\begin{array}{l}\text { Pakistan } \\
\left(+5 \cdot 2 \% \text { for UK births }{ }^{3}\right)\end{array}$ & 6648 & $4 \cdot 1$ \\
\hline $\begin{array}{l}\text { Caribbean } \\
\left(+50 \cdot 7 \% \text { for UK births }{ }^{3}\right)\end{array}$ & 4125 & $2 \cdot 5$ \\
\hline Other races* & 139850 & $86 \cdot 5$ \\
\hline
\end{tabular}

* Includes Europeans, Bangladeshis, and others, including those of mixed race.

Caribbean fathers and white mothers. The Indians in the West Midlands had come from the north of the Asian subcontinent, so they, like the Pakistanis, are racially defined as Caucasians rather than as Dravidians. Unlike the Pakistanis, however, they come from many different areas of India, particularly from the states of Punjab and Gujerat, and from the areas around Kanpur and Bombay.

The numbers of boys expected to belong to different races on the basis of the distribution provided by the 1981 census and adjusted for ethnic minorities born in the UK were: 12 Indians, seven Pakistanis, five Afro-Caribbeans, and 152 boys of other races (table 3 ). The observed distribution was significantly different from that expected $(p<0.001)$ and was mainly accounted for by the high number of Indian patients, which was double that expected.

The overall incidence of DMD in the West Midlands for boys born in the period 1978 to 1981 inclusive was 1 in 3761 , based on a total of 43 patients. The incidence in Indians was 1 in 1388 (eight patients), in Pakistanis 1 in 6648 (one patient), in Afro-Caribbeans 1 in 4125 (one patient), and in the remainder it was 1 in 4363 (33 patients).

It has not been possible to document DMD mutations in all affected boys, nor to clarify the carrier status of all mothers. The available data show that of the 13 Indian patients who were investigated, nine have deletions detected by a PCR method which detects $98 \%$ of all deletions; both the two Pakistani boys who were tested have deletions of the DMD gene, and so did one of the three patients of mixed AfroCaribbean/white origin. No deletion was found in the single Afro-Caribbean patient of pure race. The PCR method used detects deletions in $65 \%$ of all DMD patients in the West Midlands. Of the mothers tested, nine of 16 Indians were identified as carriers and so

Table 3 Racial breakdown in boys with Duchenne muscular dystrophy in the West Midlands 1970 to 1985.

\begin{tabular}{lcc}
\hline & No expected & No observed* \\
\hline Indians & 12 & $24(19)$ \\
Pakistanis & 7 & $3(3)$ \\
Afro-Caribbeans $\dagger$ & 5 & $1(1)$ \\
Other races & 152 & $148(145)$ \\
\hline
\end{tabular}

$\chi^{2}$ analysis. Overall $\chi^{2}=17 \cdot 1, \mathrm{p}<0 \cdot 001$.

Excluding Indians $\chi^{2}=4.8, p>0.05$.

* Numbers of families are in brackets.

+ There were also three offspring of mixed Caribbean/white unions who have been included as 'other races'. were the one Afro-Caribbean mother, and two of the three English mothers with Afro-Caribbean partners. The three Pakistani mothers were probably not carriers.

\section{Discussion}

It is most unusual for an $\mathrm{X}$ linked disorder to display different frequencies in different races, yet our results show a statistically significant excess of cases of Duchenne muscular dystrophy among Indian boys in the West Midlands. The overall prevalence of DMD in the West Midlands is 1 in 3761 which is comparable to previous studies worldwide, recently summarised by Emery. ${ }^{4}$ This review showed no significant racial differences, but none of the studies was from the Asian subcontinent and, to our knowledge, data of the incidence of $\mathrm{DMD}$ in Indians have not been published. Our incidence figures for other racial groups are subject to a wide margin of error as the number of cases is few, but the small number of Pakistani patients is interesting.

We have considered several possible explanations for the observation that DMD is unexpectedly common in Indians. Firstly, it may be that this immigrant group has received less genetic counselling, or has shown different responses to genetic counselling compared to the rest of the population. However, one might have expected Pakistanis or Afro-Caribbeans to show similar responses. None of the Indian families had a relative with DMD in an earlier generation. Eleven of the 27 had affected brothers, a proportion which is similar to that found earlier among all affected families in the West Midlands. ${ }^{5}$ In five of the six Indian families with two or more affected brothers, the diagnosis in the oldest had occurred after the youngest had been conceived. In the other family, the offer of genetic counselling was declined after the diagnosis, and another affected son was born 18 months later. This is the only Indian family who did not respond to genetic counselling.

Secondly, it could be that more handicapped Indians are being brought to the West Midlands, but this should be similar for all three racial groups, and there is no obvious reason why the West Midlands should be particularly attractive. None of the Indian families was known to be related to another to account for any excess of cases.

Thirdly, could the observations be the result of a disproportionate number of English patients being referred out of the region? This is possible, but it is not likely to account for any 'missed' English cases, since we ascertained patients who had been referred to the Family Care Officers for social help as well as those referred for genetic counselling.

The most likely explanation for the excess of Indian patients is that there really is an increased frequency of DMD in Indians. What might be the factor which predisposes Indians to mutations at the DMD locus or to mutations of the dystrophin gene that cause Duchenne rather than Becker muscular dystrophy? In considering possible mechanisms, 
the probable increased occurrence of mixed marriages among the ancestors of DMD patients should be noted. Of the three patients in the Malaysian Sikh family described by Miciak et al, ${ }^{1}$ two were the offspring of Sikh/ European couples. Two of the four pedigrees of multiple cases of DMD reported by Zatz et $a l^{6}$ contained mixed Negro/Caucasian marriages ( $M$ Zatz, personal communication). A large DMD pedigree in the West Midlands originated from a missionary who went to Polynesia and returned with a Polynesian wife. Of the four Afro-Caribbean DMD patients in the West Midlands, three were the offspring of mixed marriages, a much greater proportion than the $15 \%$ expected.

An explanation for the propensity to DMD mutations in Indians could be the presence of repetitive elements in the wild type gene, predisposing to mismatching and thereby to a pathogenic deletion or duplication. However, the numbers of deletions in the Indian patients was not excessive. Duplications in the dystrophin gene were not detected by the PCR methods in routine use and so a hypothesis of excess duplications could not be tested. It would be interesting to discover if the $\mathrm{Xp} 21$ haplotypes of Indians are different from those of other races. Another but less likely explanation for the excess of DMD in Indians is the presence of transposons that are specifically pathogenic for the DMD gene. Edwards ${ }^{7}$ (personal communication) has pointed out that mismatches, and the pathogenic effect of transposons, are more likely to occur when there is admixture by chromosomes from a different subspecies; the development of a pathogenic mutation in this way would not necessarily occur in the first generation. In respect of this hypothesis, the low prevalence of DMD in Pakistanis is particularly interesting. For it is possible that through their cultural pattern of marrying relatives they may have gained some protection from mismatching or from the deleterious effects of transposons.

We thank Professor J H Edwards for stimulating discussions and for his advice on this manuscript.

1 Miciak A, Keen A, Jadayel D, Bundey S. Multiple mutation in an extended Duchenne muscular dystrophy family. $\mathcal{F}$ Med Genet 1992;29:123-6.

2 Census 1981. County reports. Tables 11. London: HMSO, 1981.

3 Bundey S, Alam H, Kaur A, Mir S, Lancashire RJ. Race, consanguinity and social features in Birmingham babies; basis for a prospective study. $f$ Epidemiol Community Health 1990;44:130-5.

4 Emery AEH. Population frequencies of inherited neuromuscular diseases - a world survey. Neuromusc Dis 1991;1:19-29.

5 Bundey S. A genetic study of Duchenne muscular dystrophy in the West Midlands. $\mathcal{F}$ Med Genet 1981;18:1-7.

6 Zatz M, Passos-Bueno MR, Rapaport D, Vainzof M. Familial occurrence of Duchenne dystrophy through paternal lial occurrence of Duchenne dystrophy through pate
lines in four families. Am $\mathcal{F}$ Med Genet 1991;38:80-4.

7 Edwards JH. Familiarity, recessivity and germinal mosaicism. Ann Hum Genet 1989;53:33-47. 